\title{
Validating a set of tools designed to assess the perceived quality of training of pediatric residency programs
}

\author{
Liviana Da Dalt ${ }^{*}$, Pasquale Anselmi², Sara Furlan², Silvia Carraro ${ }^{1}$, Eugenio Baraldi', Egidio Robusto² \\ and Giorgio Perilongo ${ }^{1}$
}

\begin{abstract}
Background: The Paediatric Residency Program (PRP) of Padua, Italy, developed a set of questionnaires to assess the quality of the training provided by each faculty member, the quality of the professional experience the residents experienced during the various rotations and the functioning of the Resident Affair Committee (RAC), named respectively: "Tutor Assessment Questionnaire" (TAQ), "Rotation Assessment Questionnaire" (RAQ), and RAC Assessment Questionnaire". The process that brought to their validation are herein presented.

Method: Between July 2012 and July 2013, 51 residents evaluated 26 tutors through the TAQ, and 25 rotations through the RAQ. Forty-eight residents filled the RAC Assessment Questionnaire. The three questionnaires were validated through a many-facet Rasch measurement analysis.

Results: In their final form, the questionnaires produced measures that were valid, reliable, unidimensional, and free from gender biases. TAQ and RAQ distinguished tutors and rotations into 5-6 levels of different quality and effectiveness. The three questionnaires allowed the identification of strengths and weaknesses of tutors, rotations, and RAC. The agreement observed among judges was coherent to the predicted values, suggesting that no particular training is required for developing a shared interpretation of the items.

Conclusions: The work herein presented serves to enrich the armamentarium of tools that resident medical programs can use to monitor their functioning. A larger application of these tools will serve to consolidate and refine further the results presented.
\end{abstract}

Keywords: Evaluation tools, Validation study, Many-facet Rasch model, Pediatric residency program, Teaching faculty

\section{Introduction}

The fundamental issue of monitoring and evaluating the quality of training provided by accredited post-graduate medical training programs remains widely unsolved, at least in Europe. A variety of components contribute to the quality of the training; thus, a comprehensive articulated multi-dimensional system should be conceived to assess it. Periodic, "proxy-evaluations" by an independent third party is the inspiring model adopted by those countries in which the issue has been or is going to be

\footnotetext{
* Correspondence: liviana.dadalt@unipd.it

'Paediatric Residency Program, Department of Woman's and Child's Health, University of Padua, Via Giustiniani 3 - 35128, Padua, Italy

Full list of author information is available at the end of the article
}

addressed [1]. Concurrently, tools to evaluate at least some of the components determining the quality of the training, notably, the teaching performance of the faculty, have been validated and largely developed [2-9].

The Paediatric Residency Program (PRP) of the University of Padua, in Italy, while waiting for having the proxyevaluation system implemented, addressed the issue of monitoring and evaluating the quality of the training by having the program going through a periodic, systematic ISO:9001 certification process [10]. Furthermore, it implemented a comprehensive evaluation system [11]. This system targets the following components: i) the residents' knowledge and performance; ii) the quality of the teaching provided by the Faculty, iii) the quality of professional experience maturated 
during each rotation they go though and iv) of the functioning of the Resident Affair Committee (RAC), the body in charge of running the program. The "In-training examination", provided by the American Board of Paediatrics, is the tool adopted to evaluate the residents' knowledge [12], while, for evaluating all the other components of the program, a series of web-based ad hoc questionnaires has been developed.

Herein, we describe the results of the validation process of the questionnaires, which were elaborated to evaluate the quality of teaching provided by the Faculty, the rotations and the functioning of the RAC: named respectively the "Tutor Assessment Questionnaire" (TAQ), the "Rotation Assessment Questionnaire" (RAQ), and the "RAC Assessment Questionnaire". The validation of these tools is a fundamental pre-requisite to implement their use. The validation of the questionnaire elaborated to evaluate residents' performance has been already published [11].

\section{Methods}

The PRP of the University of Padua is a 5-year national accredited program for post-graduate training in Pediatrics. Approximately $80 \%$ of learning activities takes place in the clinical setting, practicing medicine under faculty's supervision with the ultimate goal of increasing the levels of responsibilities throughout training. The remaining learning activities include formal lectures (e.g. ground rounds and ward lectures), seminars, workshops and personal studies. Residents rotate through 15 of the 25 Divisions/Services of the Department of Woman's and Child's Health of Padua and of the affiliated Hospitals during their first three years; rotations range in time from three to six months. During the last two years of training, residents select elective rotations involving at most three divisions, each lasting from six to twelve months. The "tutors" under evaluation by the residents were the senior members of the Faculty in charge of running the service and of organizing and supervising the activity of the residents. Tutors have also the responsibility of providing the residents initiating the rotation with clear information regarding the learning objectives and the way the service is organised and the rotation planned. The RAC is composed by the Program Director, three faculties and the chief resident. It has the ultimate responsibility of running the PRP.

The three questionnaires, TAQ, RAQ and the RAC Assessment Questionnaire, consist of 9, 12, and 15 items respectively. They were constructed in order to be easy to complete and minimally time consuming. Participants rated each items on a five-point scale from 1 ("poor") to 5 ("excellent"; see Additional file 1); the last item of each questionnaire asked for an overall comprehensive judgment. The residents were given brief instructions about completing the questionnaires.
In Italy, the academic year for residents goes from July to June. The data used for validating the three questionnaires were collected between July 2012 and July 2013. Residents completed the TAQ and the RAQ within two weeks by the end of each rotation and, the RAC Assessment Questionnaire, yearly, within two weeks by the end of the academic year. Albeit the questionnaires were not anonymous, it was up to the RAC to ensure that the individual resident was unrecognizable when providing feed-backs to the Faculty.

A many-facet Rasch measurement (MFRM, [13]) analysis was used for the validation of the questionnaires. Peculiar features of Rasch models (e.g., transformation of ordinal raw scores into interval measures, identification of poorly functioning items, reproducibility of results across samples and items, investigation of response behavior) make them valuable tools in both the analysis of clinical data [14-17], and the development and evaluation of instruments [18-21].

\section{Many-Facet Rasch Measurement (MFRM)}

The MFRM [13] is a formal model for transforming nonlinear, scale-dependent ordinal raw scores into linear, scale-free interval measures. In its basic form, the model represents the probability $P_{n i j k}$ of an examined $n$ being given by judge $j$ a score $k$ on an item $i$ as an effect of the ability of examined $n\left(\beta_{n}\right)$, the difficulty of item $i\left(\delta_{i}\right)$, the severity of judge $j\left(\gamma_{j}\right)$, and the impediment in giving a score $k$ rather than $k-1\left(\tau_{k}\right)$ :

Examined, judges, and items are facets. In the analyses that follow, the residents are the judges and, according to the questionnaire under consideration, the tutors, the rotations or the RAC are the examined. Facets concerning the gender of residents $(\varepsilon)$, and the year in the program $(\zeta)$ are considered as well.

The MFRM analyses are performed using the computer program Facets 3.71.3 [22]. A measure is computed for each element of each facet. Greater measures mean more positive evaluations for examined, greater difficulty (i.e., fewer positive evaluations) for items, and greater severity for judges (residents).

The validation of each of the three questionnaires has been conducted by taking into account aspects concerning the functioning of the items and that of the response scale, the dimensionality, reliability and construct validity of the questionnaire [11].

The functioning of the items is assessed using item mean square fit statistics (infit and outfit). Values greater than 1.4 suggest that the item degrades the measurement system, or that it assesses a construct that is different from the principal one being measured (Rasch dimension) [23]. Principal component analyses of standardized residuals are also run, where contrasts in the residuals with values greater than 3 are indicative of multidimensionality [24]. 
The functioning of the response scale is assessed by determining whether the step calibrations $\tau_{k}$ are ordered or not. If they are not ordered, the response scale is not adequate for the measurement purpose [25]: for instance, the highest rating scale categories are not the most probable ones for the examined with the highest levels of performance.

Reliability of each questionnaire is assessed by examining the spread of examined measures on the latent variable. Internal consistency is assessed by means of the indexes separation reliability $(R)$ and strata of examined. When there are not missing data, $R$ is the Rasch equivalent of Cronbach's $\alpha$ [26]. Strata evaluates the number of statistically distinct groups of examined that the questionnaire is able to discern [27]. For instance, Strata $=2$ means that the questionnaire is able to discern the best examined from the worst. Inter-rater reliability is assessed by comparing the observed percentage of agreement among judges with that expected when their different degrees of severity are taken into account.

Construct validity of each questionnaire is assessed by examining the spread of the item difficulties along the latent variable. In particular, the item strata identify the number of statistically distinct groups of item difficulties that the judges can discern. In addition, bias interaction analyses are performed in order to investigate whether the functioning of the items differs with the gender of judges. The first test provides information about content representativeness, whereas the second test provides information about construct reproducibility [26-28].

It is a requirement of the Italian Law on Post-graduate Medical Residency Programs to set evaluation system. As a such, the study presented was not considered a research proposal to be approved by Ethical Committee. However, we submitted our Comprehensive evaluation program to the Institutional Review Board of our University and we received an informal approval.

\section{Results}

Validation of the Tutor Assessment Questionnaire (TAQ)

Fifty-one residents (47 females, No. 14, 14, 10, 9, 4 for 1 st to 5 th year residents, respectively) evaluated 26 tutors. Each resident evaluated from 1 to 6 tutors, and each tutor received from 1 to 16 evaluations. Given the longer duration of rotations, a smaller number of evaluations was provided by the residents of the last two years. The data matrix had dimensions 159 (overall number of evaluations) $\times 9$ (items) .

The functioning of Item 1 ("[The tutor] respects time tables of the collective activities) changed with the gender of residents. In particular, male residents provided more severe evaluations than female residents $(t(19)=2.17, p<.05)$. A new analysis was run without item 1 . The remaining 8 items defined a substantively unidimensional scale (the first contrast in the residuals had a value of 2), and none of them exhibited misfit.

The step calibrations were ordered $\left(\tau_{\text {poor-mediocre }}=-\right.$ $1.04 ; \tau_{\text {mediocre-respectable }}=-.84 ; \tau_{\text {respectable-good }}=-.19$; $\left.\tau_{\text {good-excellent }}=2.07\right)$. Therefore, residents used adequately the response scale.

Locations of residents, tutors and items on the latent variable are depicted as below (see Table 1).

Greater measures for residents indicate that they were more severe; greater measures for tutors indicate that they received more positive evaluations, and greater measures for items indicate that they were more difficult. Table 2 reports the summary statistics for the eight items. Overall, tutors received more positive evaluations on Item 7 ("[The tutor] promotes autonomy and accountability") and less positive evaluations on Item 8 ("[The tutor] encourages performing invasive procedures"). These eight items allowed the residents to identify almost seven levels of different quality (strata $=6.93$ ). Moreover, they provided a reliable evaluation of tutors $(R=.92)$, and allowed the distinction of tutors in almost five levels.

Although residents differed in severity $\left(\chi^{2}(50)=645.4\right.$, $p<.001)$, the observed agreement among them is in line with that expected $(\operatorname{Exp}=28.4 \%$; Obs $=29 \%)$. The severity of residents did not change with their gender $\left(\mathrm{X}^{2}(1)=.6, p=.45\right)$, but with the year of program that they were attending $\left(X^{2}(4)=26.6, p<.001\right)$.

\section{Validation of the Rotation Assessment Questionnaire (RAQ)} Fifty-one residents (46 females; No. 14, 14, 10, 9, 4 for 1 st to 5 st year residents, respectively) evaluated 25 rotations. Each resident evaluated from 1 to 7 rotations, and each rotation received from 1 to 16 evaluations. The data matrix had dimensions 164 (overall number of evaluations) $\times 12$ (items).

The value of the first contrast in the residuals was 2.9 , very close to the criterion indicative of multidimensionality. In addition, Item 3 ("rotation was organized as declared"), Item 4 ("Teaching activities were regularly delivered"), and Item 11 ("The rotation] allowed participation in other cultural activities of the program") exhibited misfit (infit $=1.43$, outfit $=1.52$ for Item 3 ; infit $=1.46$, outfit $=1.51$ for Item 4 ; infit $=$ 1.85 , outfit $=2.09$ for Item 11 ). These items were excluded and a new analysis was run. The infit of Item 7 ("[The rotation] contributed to improve my clinical skills") exceeded the criterion of 1.4. However, its value (1.47) is not so large to require the removal of the item from the pool. The 9 items defined a substantively unidimensional scale (the value of the first contrast decreased from 2.9 to 2.1), and none of them exhibited differential gender functioning.

The step calibrations were ordered $\left(\tau_{\text {poor-mediocre }}=-\right.$ $1.42 ; \tau_{\text {mediocre-respectable }}=-1.15 ; \tau_{\text {respectable-good }}=-.05$; 
Table 1 Validation of the Tutor Assessment Questionnaire (TAQ) - Locations of residents, tutors and items on the latent variable

\begin{tabular}{|c|c|c|c|}
\hline Measure & Resident & Tutor & Item \\
\hline 4 & & $\mathrm{~T} 13$ & \\
\hline \multirow[t]{2}{*}{3} & & $\mathrm{~T} 23$ & \\
\hline & & T9 & \\
\hline \multicolumn{4}{|l|}{2} \\
\hline & & T21 & \\
\hline & R50 & & \\
\hline & R9 & & \\
\hline & R21 & T24 & \\
\hline \multirow[t]{5}{*}{1} & & T3 & $\begin{array}{l}\text { [Encourages performing } \\
\text { invasive procedures] }\end{array}$ \\
\hline & R36 & T27 T11 & \\
\hline & R16 & & [Regularly gives ward lectures] \\
\hline & R28 R27 & $\mathrm{T} 22$ & \\
\hline & R32 R51 R1 & & \\
\hline \multirow[t]{5}{*}{0} & R30 & $\mathrm{T} 25$ & $\begin{array}{l}\text { [Reviews clinical documentation] } \\
\text { [Scrutinizes clinical problems] }\end{array}$ \\
\hline & R5 R44 & $\begin{array}{l}\text { T20 T17 } \\
\text { T26 T12 }\end{array}$ & [Effective in conducting lectures] \\
\hline & $\begin{array}{l}\text { R45 R11 R22 } \\
\text { R24 R52 }\end{array}$ & T18 T10 & $\begin{array}{l}\text { [Overall judgment] [Promotes } \\
\text { self-education] }\end{array}$ \\
\hline & R46 R48 & T4 T7 & $\begin{array}{l}\text { [Promotes autonomy and } \\
\text { accountability ] }\end{array}$ \\
\hline & $\begin{array}{l}\text { R37 R8 R26 R10 } \\
\text { R29 R3 }\end{array}$ & T8 & \\
\hline \multirow[t]{4}{*}{-1} & $\begin{array}{l}\text { R31 R2 R43 R34 } \\
\text { R49 }\end{array}$ & $\begin{array}{l}\text { T15 T5 } \\
\text { T6 }\end{array}$ & \\
\hline & R6 R7 R4 R23 & $\mathrm{T} 2 \mathrm{~T} 16$ & \\
\hline & $\begin{array}{l}\text { R15 R40 R14 } \\
\text { R18 }\end{array}$ & T14 & \\
\hline & $\begin{array}{l}\text { R47 R33 R13 } \\
\text { R42 }\end{array}$ & $\mathrm{T} 1$ & \\
\hline \multirow[t]{4}{*}{-2} & & & \\
\hline & R38 & & \\
\hline & R17 & & \\
\hline & R20 & & \\
\hline \multirow[t]{2}{*}{-3} & $\mathrm{R} 12$ & & \\
\hline & R19 & & \\
\hline \multirow[t]{2}{*}{-4} & R39 & & \\
\hline & R35 & & \\
\hline-5 & R41 & & \\
\hline
\end{tabular}

$\left.\tau_{\text {good-excellent }}=2.61\right)$. Therefore, the response scale had been adequately used by residents.

Locations of residents, rotations and items on the latent variable are depicted as below (see Table 3 ).

Greater measures for rotations indicate that they received more positive evaluations. The measures of residents and
Table 2 Average scores, item measures, standard errors and fit statistics of the Tutor Assessment Questionnaire (measure order)

\begin{tabular}{lllllll}
\hline Item & $\begin{array}{l}\text { Average } \\
\text { score }\end{array}$ & Measure & SE & Infit & Outfit \\
\hline $\begin{array}{l}\text { 8 [Encouragesinvasive } \\
\text { procedures] }\end{array}$ & 2.8 & .98 & .09 & 1.30 & 1.21 \\
$\begin{array}{l}\text { [Regularly gives ward } \\
\text { lectures] }\end{array}$ & 3.1 & .58 & .09 & 1.19 & 1.29 \\
$\begin{array}{l}\text { [Reviews clinical } \\
\text { documentation] }\end{array}$ & 3.5 & .05 & .10 & 1.05 & 1.09 \\
4 [Scrutinizes clinical problems] & 3.5 & -.05 & .10 & .87 & .86 \\
3 [ls effective in conducting & 3.7 & -.23 & .10 & 1.16 & 1.16 \\
lectures] & & & & & \\
9 [Overall judgment] & 3.7 & -.36 & .10 & .51 & .52 \\
5 [Promotes self-education] & 3.7 & -.37 & .10 & .70 & .74 \\
7 [Promotesautonomy and & 3.9 & -.60 & .11 & 1.02 & 1.15 \\
accountability] & & & & &
\end{tabular}

Note. Greater measures indicate more difficult items (i.e., that received fewer positive evaluations).

items read as in Table 1 . Table 4 contains summary statistics for the 9 items. On the whole, the rotations received more positive evaluations on Item 9 ("[The rotation] has been a enriching experience from a human point of view") and less positive evaluations on Item 7 ("[The rotation] contributed to improve my clinical skills"). These 9 items allowed the residents to distinguish ten qualitatively different levels in the rotation quality (strata $=10.02)$. In addition, they provided a reliable evaluation of rotations $(R=.95)$, and allowed to distinguish them in almost six groups of different quality (strata $=5.88$ ).

The residents differed in severity $\left(\chi^{2}(50)=749.8, p<.001\right)$, but the observed agreement among them is in line with that expected $(\operatorname{Exp}=34.6 \%$; Obs $=34.9 \%)$. Male and female residents did not differ in severity $\left(\chi^{2}(1)=1.0, p=.31\right)$. There were some differences among residents attending different years of program, but they were not reliable $\left(\chi^{2}(4)=16.6\right.$, $p<.01 ; R=.35)$.

\section{Validation of the RAC Assessment Questionnaire (RACAQ)}

Forty-eight residents (42 females; $\mathrm{N}=14,13,8,11,2$ for 1 st to 5 th year residents, respectively) evaluated the RAC. The data matrix had dimensions 48 (evaluations) $\times 15$ (items).

The functioning of Item 14 (Scoring "the teaching attitude of the faculty") changed with the gender of residents (i.e., males provided more severe evaluations than females; $t(7)=2.38, p<.05)$, whereas Item 5 ("[The RAC] It provides residents with individualized feedbacks regarding the evaluation they received") exhibited misfit (infit $=1.64$, outfit $=1.66$ ). These two items were excluded and a new analysis was run. The remaining 13 items defined a substantively 
Table 3 Validation of the Rotation Assessment Questionnaire (RAQ) - locations of residents, rotations and items on the latent variable

\begin{tabular}{ll}
\hline Measure Resident & Rotation Item \\
\hline 5 & $\mathrm{RO} 23$ \\
4 & \\
3 &
\end{tabular}

R9 RO24

RO9 [lt contributed to improve clinical skills]

\section{$\mathrm{RO} 21 \mathrm{RO} 22$}

$\mathrm{RO} 3$

RO26 RO20

$\mathrm{RO}$ RO25

$\mathrm{RO} 4 \mathrm{RO} 27$

[A clear definition of learning objectives provided] [Learning objectives met]

[Overall judgment] [It served to improve professional competences]

[lt contributed to improves pediatric knowledge] [lt encouraged personal studies]

[lt has been an educational experience] [lt has been an enriching experience RO19 R017 from a human point of view]

\section{RO18 RO12}

RO5 RO16

\section{RO15 RO1}

$\mathrm{RO} 2$

$\mathrm{RO} 14$

$\begin{array}{ll} & \text { R34 R20 R13 } \\ & \text { R40 } \\ & \text { R15 } \\ -3 \quad & \text { R12 R31 } \\ & \text { R42 } \\ & \text { R25 } \\ & \text { R38 R17 } \\ & \text { R35 } \\ -4 & \\ -5 & \text { R39 R19 }\end{array}$


Table 5 Validation of the RAC Assessment Questionnaire Locations of residents and items on the latent variable

\begin{tabular}{lll}
\hline Measure & Resident & Item \\
\hline 3 & & \\
& R25 & \\
& R15 & [lt cares of individual resident] \\
& R28 & \\
& R19 R23 & [Evaluation system] \\
& R16 & \\
& [Opportunities for confrontation] \\
& R47 R33 & [Teaching attitude of the faculty] \\
& [Actions for continuous quality \\
& improvement of training activity] \\
& [Professional guidance] \\
& [rotation plan in time]
\end{tabular}

R2

R27 R48 R6 R42

$0 \quad$ R44 R30 R41

R31 R38 R3

R40

R26 R21

R39

R5 R11 R22 R34

R8 R35

R13 R4 R12

R17

R29 R10 R43

R9 R45

$\begin{array}{ll}-2 & \text { R36 }\end{array}$

R18 R46

R7 R20

R1

$-3$

R24

$-4$

R32

$-5$

$-6$

$-7$

R37 R14

the functioning of the RAC within the context of the Paediatric Residency Program of the University of Padua. In their final form, the questionnaires produced unidimensional measures and our results suggest that they are valid and reliable evaluation tools. TAQ and RAQ allowed reliable assessments of tutors and rotations, and distinguished them into 5-6 levels of different quality.
Table 6 Average scores, item measures, standard errors and fit statistics of the RAC Assessment Questionnaire (measure order)

\begin{tabular}{llllll}
\hline Item & $\begin{array}{l}\text { Average } \\
\text { score }\end{array}$ & Measure & SE & Infit & Outfit \\
\hline $\begin{array}{l}\text { [ [lt cares of individual } \\
\text { residents] }\end{array}$ & 2.8 & 1.54 & .22 & .98 & .98 \\
13 [Systems of evaluation] & 2.9 & 1.29 & .23 & .95 & 1.01 \\
3 [lt provides opportunities & 3.1 & .84 & .23 & .82 & .82 \\
of confrontation...] & & & & & \\
12 [Quality score of the formal & 3.1 & .84 & .23 & 1.41 & 1.35 \\
lessons] & & & & & \\
7 [Actions to improve the & 3.2 & .61 & .23 & .92 & 1.02 \\
quality of training] & & & & & \\
$\begin{array}{l}\text { 6[Professional guidance] } \\
\text { 2[Rotation plan] }\end{array}$ & 3.3 & .52 & .24 & 1.02 & 1.04 \\
9 [Quality score of the & 3.3 & .41 & .24 & 1.13 & 1.20 \\
rotations] & 3.4 & .07 & .24 & 1.13 & 1.18 \\
15 [Overall judgment] & 3.6 & -.50 & .26 & .55 & .54 \\
8 [Overall quality of the & 3.7 & -.68 & .26 & .72 & .65 \\
training] & & & & & \\
11 [Quality score of the & 3.8 & -1.10 & .27 & 1.04 & .92 \\
cultural environment] & & & & & \\
1 [Formal lectures plan] & 3.9 & -1.48 & .28 & 1.04 & .97 \\
10 [Autonomy and reliability] & 4.1 & -2.37 & .29 & 1.16 & 1.13 \\
\hline
\end{tabular}

Note. Greater measures indicate more difficult items (i.e., that received fewer positive evaluations).

In brief, the three questionnaires provided a reliable assessment of the strengths and of the weaknesses of the tutors, the rotations, and the RAC. The agreement observed among judges was coherent to the predicted values. The usage of the questionnaires is immediate and does not require to train judges to have a shared interpretation of the items.

The MFRM represents a valuable tool for the validation of these questionnaires. Being a Rasch model, the MFRM allows transforming ordinal raw scores into interval measures. This is a relevant feature of the model since researchers showed serious concerns toward measuring ordinal raw scores as they were interval measures $[29,30]$. Erroneous conclusions may derive from applying parametric analyses to ordinal data [31]. In addition, the MFRM estimates judge severity and removes it from the measurement [13]. This allows the elimination of the dependence of the evaluations on the severity of judges, which is a serious concern when the different judges evaluate different persons. It is worth noting that Rasch models are especially demanding of data that satisfy the requirements for constructing measures [32]. The items removed during the validation process are an example of data that do not adequately conform to the model.

In conclusion, the data herein presented allows us to be confident, upon further internal refining, of the validity of 
these questionnaires for other Italian pediatric residency programs. Thus, the work presented served to enrich the armamentarium of tools the resident medical programs can use to monitor their functioning. Their larger application is now needed in order to consolidate and further refine the data herein presented. The development and validation of these tools is indeed a sort of continuous exercise. The challenge of documenting how faculty and the RAC respond to the feed-backs generated by these tools and ultimately, their impact on the quality of the training, and above all, on the quality of the pediatricians licensed by the program, remains an open issue to face with [33,34].

\section{Additional file}

Additional file 1: Tutor Assessment Questionnaire; Rotation Assessment Questionnaire; Resident Affaire Committee Assessment Questionnaire.

\section{Competing interests}

The authors declare that they have no competing interest.

\section{Authors' contributions}

LDD \& GP - Vice-chairmen of the Resident Affair Committee of the Pediatric Residency Program of the Department of Woman's and Child's Health of the University of Padua - Personal involvement in designing the entire evaluation process of the program, in setting the contents of each questionnaire, in interpreting the data and in writing the manuscript. EB \& SC - Chairman of the Resident Affair Committee and member of the resident Affair Committee, respectively, of the Pediatric Residency Program of the Department of Woman's and Child's Health of the University of Padua; personal involvement in running the program and in the evaluation process. PA, SF, ER - Research Assistants and Full Professor, respectively; personal involvement in the validation process of the questionnaire and in writing this report. All authors read and approved the final manuscript.

\section{Author details}

${ }^{1}$ Paediatric Residency Program, Department of Woman's and Child's Health, University of Padua, Via Giustiniani 3 - 35128, Padua, Italy. ${ }^{2}$ Department FISPPA, University of Padua, Padua, Italy.

Received: 26 July 2014 Accepted: 18 December 2014

Published online: 20 January 2015

\section{References}

1. Weiss KB, Wagner R, Nasca TJ. Development, testing, and implementation of the ACGME Clinical Learning Environment Review (CLER) program. J Grad Med Educ. 2012;4:396-8.

2. Snell L, Tallett S, Haist S, Hays R, Norcini J, Prince $K$, et al. A review of the evaluation of clinical teaching: new perspectives and challenges. Med Educ. 2000;34:862-70.

3. Ghosh AK, Beckman TJ, Cook DA, Erwin PJ, Mandrekar JN. How reliable are assessments of clinical teaching? A review of the published instruments. J Gen Intern Med. 2004;19:971-7.

4. Lombarts KM, Bucx MJ, Arah OA. Development of a system for the evaluation of the teaching qualities of anesthesiology faculty. Anesthesiology. 2009;111:709-16.

5. Fluit CR, Bolhuis S, Grol R, Laan R, Wensing. Assessing the quality of clinical teachers: a systematic review of content and quality of questionnaires for assessing clinical teachers. J Gen Intern Med. 2010;25:1337-45.

6. Arah OA, Hoekstra JBL, Bos AP, Lombarts KM. New tools for systematic evaluation of teaching qualities of medical faculty: results of an ongoing multi-center survey. PLoS ONE. 2011;6:e25983.

7. Nation JG, Carmichael E, Fidler H, Violato C. The development of an instrument to assess clinical teaching with linkage to CanMEDS roles: a psychometric analysis. Medical Teacher. 2011;33:e290-6.
8. van der Leeuw R, Lombarts K, Heineman MJ, Arah O. Systematic evaluation of the teaching qualities of obstet- rics and gynecology faculty: Reliability and validity of the SETQ tools. PLOS ONE. 2011;6:e19142.

9. Boerebach BC, Arah OA, Busch OR, Lombarts KM. Reliable and valid tools for measuring surgeons' teaching performance: residents' vs. self Evaluation. J Surgical Education. 2012;69:511-20.

10. Da Dalt L, Callegaro S, Mazzi A, Scipioni A, Lago P, Chiozza ML, et al. A model of quality assurance and quality improvement for post-graduate medical education in Europe. Med Teach. 2010;32:e57-64.

11. Da Dalt L, Anselmi P, Bressan S, Carraro S, Baraldi E, Robusto E, et al. A short questionnaire to assess pediatric resident's competencies: the validation process. Ital J Pediatr. 2013;5:39-41.

12. American Board of Pediatrics. The General Pediatrics International In-training Examination (I-ITE). [http://abp-intl.org/intrainingexamination.html], (last access June 4, 2014).

13. Linacre JM. Many-facet Rasch measurement. Chicago, IL: MESA Press; 1989.

14. Anselmi P, Vianello M, Voci A, Robusto E. Implicit sexual attitude of heterosexual, gay and bisexual individuals: disentangling the contribution of specific associations to the overall measure. Plos One. 2013;8:e78990.

15. Anselmi P, Vianello M, Robusto E. Preferring thin people does not imply derogating fat people. A Rasch analysis of the implicit weight attitude. Obesity. 2013;21:261-5

16. Fisher AG. The assessment of IADL motor skills: an application of many-facet Rasch analysis. Am J Occup Ther. 1993;47:319-29.

17. Heinemann AW, Linacre JM, Wright BD, Hamilton BB, Granger C. Prediction of rehabilitation outcomes with disability measures. Arch Phys Med Rehab. 1994;75:133-43.

18. Clauser BE, Ross LP, Nungester RJ, Clyman SG. An evaluation of the Rasch model for equating multiple forms of a performance assessment of physicians' patient-management skills. Acad Med. 1997;39 Suppl 1:76-8.

19. Conrad KJ, Wright BD, McKnight P, McFall M, Fontana A, Rosenheck R. Comparing traditional and Rasch analyses of the Mississippi PTSD Scale: revealing limitations of reverse-scored items. J Appl Meas. 2004;39:15-30.

20. de Morton NA, Nolan JS. Unidimensionality of the Elderly Mobility Scale in older acute medical patients: different methods, different answers. J Clin Epidemiol. 2011;39:667-74. doi:10.1016/j.jclinepi.2010.09.004.

21. Haley SM, MCHorney CA, Ware Jr JE. Evaluation of the MOS SF-36 physical functioning scale (PF-10): I. unidimensionality and reproducibility of the Rasch item scale. J Clin Epidemiol. 1994;47:671-84.

22. Linacre JM. Facets Rasch measurement computer program (Version 3.71.3) [Computer software]. Chicago, IL: Winsteps.com; 2013.

23. Wright BD, Linacre JM. Reasonable mean-square fit values. Rasch Meas Trans. 1994;8:370.

24. Linacre JM. Winsteps (Version 3.68.0) [Computer software]. Chicago, IL: Winsteps.com; 2009.

25. Linacre JM. Optimizing rating scale category effectiveness. J Appl Meas. 2002;39:85-106.

26. Smith EV. Evidence for the reliability of measures and validity of measure interpretation: a Rasch measurement perspective. J Appl Meas. 2001;39:281-311.

27. Fisher WP. Reliability statistics. Rasch Meas Trans. 1992;39:238.

28. Messick S. Validity. In: Linn RL, editor. Educational measurement. 3rd ed. New York: Macmillan; 1989. p. 13-103.

29. Forrest M, Andersen B. Ordinal scale and statistics in medical research. BMJ. 1986;39:537-8. doi:10.1136/bmj.292.6519.537.

30. Merbitz C, Morris J, Grip JC. Ordinal scales and foundations of mis-inference. Arch Phys Med Rehabil. 1989;39:308-12.

31. Kahler E, Rogausch A, Brunner E, Himmel W. A parametric analysis of ordinal quality-of-life data can lead to erroneous results. J Clin Epidemiol. 2008;39:475-80.

32. Fluit C, Bolhuis S, Grol R, Ham M, Feskens R, Laan R, et al. Evaluation and feedback for effective clinical teaching in postgraduate medical education: validation of an assessment instrument incorporating the CanMEDS roles. Med Teach. 2012;34:893-901.

33. Fluit CV, Bolhuis S, Klaassen T, DE Visser M, Grol R, Laan R, et al. Residents provide feedback to their clinical teachers: reflection through dialogue. Med Teach. 2013;35:e1485-92.

34. Asch DA, Nicholson S, Srinivas S, Herrin J, Epstein AJ. Evaluating obstetrical residency programs using patient outcomes. JAMA. 2009;302:1277-83. 